\title{
Corpus-based Research on lexical Features of English Abstract in Postgraduates' Thesis of Fashion Majors
}

\author{
Weili Zi \\ School of Language and Culture, Beijing Institute of Fashion Technology \\ No.2 Yinghua East Street, Chaoyang District, Beijing 100029, China \\ Tel: 1-362-134-2535 E-mail: zwlpost@126.com
}

Received: October 26, 2017 Accepted: November 11, 2017 Published: November 13, 2017

doi:10.5296/ijele.v5i2.12139 URL: https://doi.org/10.5296/ijele.v5i2.12139

\begin{abstract}
English abstract is the accurate summarization of an article. English Abstract writing ability is a must for postgraduates of fashion majors. This paper analyzes the features of lexical usage in English abstract of fashion-major postgraduates' thesis in terms of lexical variability and lexical density with help of corpus methodology. A small-scale corpus of 50 abstracts is built with the name English Abstract of Postgraduates' Thesis for Fashion Majors (EAPFM), which is collected from a random sample of 126 English abstracts of postgraduates' thesis between 2013 and 2015, 50 English abstracts of English Speaking Experts (EAESE) are taken as reference corpus. When analyzing the modal verbs, British Academic Written English (BAWE) is adopted as the reference corpus. The research result shows that the lexical coverage rate of academic words from English abstract of English-speaking experts is greater than that from fashion-major postgraduates' English abstract. The total types of English-speaking experts' abstracts are more than that of fashion-majors'. The frequency of the eight central modal verbs except shall from British Academic words corpus and English abstract corpus of fashion majors exhibit significant differences. What's more, central modal verbs should and will are overused while would is less used in English abstract of postgraduates' theses of fashion majors. Modal verb can is most frequently used by those of fashion majors because they are more self-assured for their research topics. This research is to strengthen the awareness of correctly used academic words of those postgraduates of fashion majors, and improve their academic writing ability by providing postgraduate teaching reform with the necessary data evidence.
\end{abstract}

Keywords: Postgraduates' thesis of fashion-major, English abstract, lexical features 


\section{Introduction}

Abstract writing is the important measurement of academic English writing ability. Academic English writing has been the weaknesses of English teaching of fashion majors, so the important topic for postgraduates' English teaching is to improve the academic English writing of fashion majors. Considering the characteristics of postgraduates' thesis of fashion majors, a small-scale corpus is built with the name English Abstract of Postgraduates' Thesis for Fashion Majors (EAPFM), which is collected from a random sample of 126 English abstracts of postgraduates' thesis between 2013 and 2015. This paper is an analysis of lexical features and usage in the English abstracts of postgraduates' theses of fashion majors from the microcosmic perspective in order to find out the current situation of their academic English learning and the characteristics of English abstract writing of this group, and thus provide the data support for the postgraduate English teaching.

\section{Research Background}

Since 2011, domestic scholars conduct many researches on abstract of academic papers or theses from diverse aspects. Such as researches on macroscopic and microcosmic analysis of academic abstracts (Niu, Zhao \& Ye, 2013:11-14; 2013:150-156; Wang, 2014:111-113; Liu \& Xu, 2015: 46-50; Li \& Cao, 2015:80-85; Zhou, 2015:45-51; Liu \& Wang, 2016: 52-60;), researches on comparative study on abstract of Chinese and foreign academic papers ( $\mathrm{Li} \&$ Josta, 2011:39-44; Xiao \& Cao, 2014:260-272; Hu, 2015:813-822; Cao \& Xiao, 2015:5-9; Guo \& Ma, 2016:39-43; Liu \& Zhang, 2016:20-26; Lu, 2017:78-82; Liu, 2011:85-88; Mu, 2016:97-107; Chen \& Wang, 2017:32-35). Some scholars focus on the modal words in abstract of academic papers (Ye, 2016; Chen, 2016; Long, Fu, Chen \& Wang, 2016), besides, there are still some scholars, such as Sun Li (2015:15-21) who are interested in pragmatic identity construction of abstracts. Above all, it is obvious there are more research findings in terms of abstract study since 2011, which involves interdisciplinary comparative researches and subjects. However, research on English abstract of postgraduates' theses related to fashion majors is paid less attention to. One of reasons for me to choose English abstract in postgraduates' thesis of fashion major as the research data is that data for abstract researches in previous papers are most collected from the authoritative academic periodicals both at home and abroad, while data from postgraduates' theses, especially theses of fashion majors are rare, and few experts focus on English abstracts research of fashion majors. As we all know, postgraduates' thesis is a must for this special group, postgraduates of fashion major, they are required to accomplish this academic writing task while completing professional learning tasks before graduation, which could reflect their actual learning. In this paper, 126 abstracts of fashion majors during 2013 and 2015 are randomly collected for lexical analysis from micro perspective, aiming to find out lexical features of English abstracts from those of fashion majors, so that we can adjust properly our teaching goal, and also provide postgraduate English teaching reform with effective reference. 


\subsection{English Abstract}

Abstract is first appeared in papers of medical field in 60s of twenty century, and commonly adopted from then on. (Niu, 2013:150-156) According to GB7713-87 (writing format of Presentation of scientific and technical reports, dissertations and scientific papers), Master's and doctoral dissertation are required to provide English and Chinese abstract. Obviously, abstract is the important part in the academic paper, also an independent passage summarizing the whole paper. It is written before the main body of a paper, serving as the indication of the whole paper in terms of content and structure. (Swales, 1990: 179-181). Academic abstract writing has a direct impact on international recognition of the paper and effective academic attention of that in the same area. Of course, English abstract, as an independent style, plays an important role in worldwide transmission and communication of Chinese academic papers, most importantly, it could effectively promote the academic internationalization.

\subsection{Software of Range and LLX2}

Range in this paper is used as the lexical analysis tool to get the academic lexical distribution. Words are analyzed based on three built-in basic lists. Basic list 1 and basic list 2 contain the first commonly used 2000 word families ( general service list, shortened for GSL ), basic list 3 is academic word list (shortened for AWL), containing 570 word family. In this paper, Range is adopted to find out the coverage and distribution of AWL in English abstracts of scientific and technological papers.

LLX2, another software developed by Beijing Foreign Studies University, which is also called log likelihood calculator. This software is used to observe the significant difference of the nine core modal verbs by frequency and their log likelihood in two corpora.

\section{Research Design}

\subsection{Research Questions}

This paper attempts to answer the following questions:

(1) Are there any differences of English abstracts in the academic writing between postgraduates of fashion majors and English speaking experts in terms of coverage of basic words and academic words?

(2) Are there any differences of English abstracts in the academic writing between postgraduates of fashion majors and English speaking experts in terms of lexical variability and lexical density?

(3) Compared to English speaking academic writing, what are the features of using modal verbs in academic writing for postgraduates of fashion majors?

\subsection{Research Subjects and Corpus Collection}

126 English abstracts of postgraduates' theses of fashion majors from 2013 to 2015are 
collected as the research data in this study, including three major orientations: 39 English abstracts of costume engineering, 28 of artistic design theories and 59 of art of designing. All theses come from Beijing Institute of Fashion Technology. 50 abstracts are collected randomly from 126 abstracts when compared with English speaking abstracts. English speaking abstracts are collected from columns of Clothing and Fashion, art and photography, Design and Graphic Design, Communication and Media Study in Wiley Online Library and EBSCOhost in BIFT library, from which 50 abstracts of costume engineering, artistic design theories and art of designing are collected as the reference corpus, which is called English Abstract of English Speaking Experts (EAESE). Besides, British Academic Written English (BAWE) with 6689299 words is also adopted as reference corpus when analyzing modal verbs of fashion-majored postgraduates' English abstracts.

The steps for building the small-scale corpus are as follows: EAPFM corpus is built with 50 English abstracts with total 14533 words, 2348 types and12926 tokens. EAESE corpus is built with 50 English abstracts too with total 8953 words, 2288 types and 7872 tokens. All the English abstracts are annotated with the help of software treetagger3 for the convenience of retrieval.

\subsection{Analytical Method}

In this study, three built-in basic word lists of Range are used to find out the lexical coverage and distribution of AWL in English abstracts from postgraduates of fashion majors and English speaking experts, and a comparative analysis between them is conducted at same time. Besides, log likelihood \& Chi-square calculator is also adopted to analyze the features of nine core modal verbs in English abstract from EAPFM and BAWE.

\section{Research Results and Discussion}

\subsection{Coverage of Three-level Word Lists}

The lexical analysis tool Range is adopted to measure the coverage and distribution of three level word lists between EAPFM and EAESE, especially the different coverage and distribution of academic words in both corpuses.

Table 1. Coverage and Distribution of three-level word lists between EAPFM and EAESE

\begin{tabular}{|c|c|c|c|c|c|c|}
\hline \multirow{2}{*}{$\begin{array}{l}\text { WORD } \\
\text { LIST }\end{array}$} & \multicolumn{2}{|c|}{ TOKENS/\% } & \multicolumn{2}{|l|}{ TYPES/\% } & \multicolumn{2}{|c|}{ FAMILIES } \\
\hline & EAESE & EAPFM & EAESE & EAPFM & $\begin{array}{l}\text { EAE } \\
\text { SE }\end{array}$ & $\begin{array}{l}\text { EAPF } \\
\text { M }\end{array}$ \\
\hline one & $\begin{array}{l}7775 / 56.0 \\
0\end{array}$ & $\begin{array}{l}10215 / 69.4 \\
8\end{array}$ & $\begin{array}{l}1106 / 40.9 \\
2\end{array}$ & $1066 / 43.4$ & 548 & 587 \\
\hline two & $\begin{array}{l}1799 / 12.9 \\
6\end{array}$ & $2175 / 14.79$ & $572 / 21.16$ & $504 / 20.52$ & 297 & 336 \\
\hline three & $571 / 4.11$ & $513 / 3.49$ & $210 / 7.77$ & $190 / 7.74$ & 127 & 154 \\
\hline $\begin{array}{l}\text { not in the } \\
\text { lists }\end{array}$ & $\begin{array}{l}3738 / 26.9 \\
3 \\
\end{array}$ & $1799 / 12.24$ & $815 / 30.15$ & $696 / 28.34$ & ????? & ????? \\
\hline Total & 13883 & 14702 & 2703 & 2456 & 972 & 1077 \\
\hline
\end{tabular}


Proportion of basic word list 1 and basic world list 2 in EAPFM is greater than that in EAESE, and families of three word lists used in EAPFM is also more than that in EAESE. However, proportion of basic word list 3 in EAESE is slightly higher than in EAPFM, and lexical coverage of basic word list 3, i.e. AWL, in EAESE is greater than in EAPFM, while words not in the lists in EAESE (26.93\%) is also more than in EAPFM (12.24\%)。 The total tokens of English abstracts from EAPFM are higher than that from EAESE, while the total types and word families of the former (2456) are lower than the latter (2703). From Table 1, we can find out postgraduates of fashion majors prefer to use more basic words, although some are not used skillfully. Besides, the acquisition of academic words is not enough, because academic words in their English abstracts are less used than in English speaking academic abstracts.

Table 2. Lexical variation of English abstract between EAPFM and EAESE

\begin{tabular}{lll}
\hline WORD LIST & EAESE & EAPFM \\
\hline one & 0.070 & 0.057 \\
\hline two & 0.165 & 0.154 \\
\hline three & 0.222 & 0.300 \\
\hline
\end{tabular}

As Table 2 shows, lexical variation of word list one and two in EAESE is greater than that in EAPFM, which indicates those of fashion majors are not good at expressing meaning by using lexical conversions, and they are not flexible enough in remembering words, i.e. ways of enlarging vocabulary is limited. However, lexical variation of word list three in EAPFM is a little bigger than that in EAESE, although the amount of word list one and two for EAPFM is not satisfied enough. This shows those of fashion majors are good at using academic words, which is closely related to using a great amount of specialized vocabulary as required.

Table 3. Lexical density of English abstract between EAPFM and EAESE

\begin{tabular}{lllll}
\hline \multirow{2}{*}{ WORD LIST } & EAESE & \multicolumn{3}{l}{ EAPFM } \\
\cline { 2 - 5 } & Type/Token & TTR & Type/Token & TTR \\
\hline one & $1106 / 7775$ & 0.142 & $1066 / 10215$ & 0.104 \\
\hline two & $572 / 1799$ & 0.318 & $504 / 2175$ & 0.232 \\
\hline three & $210 / 571$ & 0.368 & $190 / 513$ & 0.370 \\
\hline Total & $2703 / 13883$ & 0.195 & $2456 / 14702$ & 0.167 \\
\hline
\end{tabular}

Table 3 shows word list 1 and word list 2 Lexical density of English abstract in EAESE is bigger than that in EAPFM, while word list 3, i.e. academic lexical density remains basically equivalent to each other. The possible reason for the result above is more interpreted languages can be found in EAPM, which results in low levels of difficulty of these abstracts. This, of course, is closely related to the characteristic of art specialty and the English proficiency of those majoring in fashion. Above all, compared with EAESE the Lexical density in total word lists for EAPFM is a little bit lower, which suggests postgraduates of fashion do not have any advantages in both variety and diversity of English words. Therefore, for those postgraduates of fashion majors, more efforts should be exerted in improving academic vocabulary. In addition, the numbers of English abstracts for EAPFM is more than 
that for EAESE, while lexical density of the former is lower than that of the latter, which shows there is still plenty of room for improvement in fashion-major postgraduates' English learning.

\subsection{Modal Verbs in Academic Writing for Postgraduates of Fashion Majors}

An abstract of thesis is a researcher's summary of the academic discovery. In abstracts, the researchers tend to express the standpoints and make evaluation and judgment by using modal verbs. The modal verbs in English have the function of evaluating and expressing positions. (Fowler, 1979: 85; Biber, 2000: 485) Modal verbs are categorized by Halliday from three perspectives, which are modal meaning, semantics and scale of modality. According to Biber (2000: 485), There are nine central modal verbs used to express modality, including can, could, may, might which means permission/possibility/ability, must, should which means obligation/necessity, and will, would, shall expressing volition/prediction.

Table 4. Log-likelihood of central modal verbs between EAPFM and BAWE

\begin{tabular}{lllllll}
\hline (105288) & EAPFM & $\begin{array}{c}\text { BAWE } \\
(17719753)\end{array}$ & & & & \\
\hline Word & Freq. & Freq. & Log-likelihood & Sig. & \\
\hline will & 44 & 10765 & 6.97 & 0.008 & $* *$ & - \\
\hline can & 106 & 13474 & 7.57 & 0.006 & $* *$ & + \\
\hline would & 6 & 9319 & 71.82 & 0.000 & $* * *$ & - \\
\hline could & 11 & 5823 & 21.89 & 0.000 & $* * *$ & - \\
\hline must & 5 & 3209 & 14.69 & 0.000 & $* * *$ & - \\
\hline should & 14 & 5011 & 10.37 & 0.001 & $* *$ & - \\
\hline may & 5 & 6754 & 49.25 & 0.000 & $* * *$ & - \\
\hline might & 1 & 1418 & 10.55 & 0.001 & $* *$ & - \\
\hline shall & 2 & 529 & 0.48 & 0.490 & & - \\
\hline
\end{tabular}

In Table 4, it is obviously that will and can in EAPFM are the first two most frequently used modal verbs, which is same with what is it like in BAWE, this suggests the common features of academic writing. However, compared with EAESE, there is significant differences in the other eight central modal verbs except shall, especially would, could, must and may.

Nine central modal verbs in EAPFM are sorted by frequency of use as follows:

can, will, should, could, would, must, may, shall, might

Nine central modal verbs in BAWE are sorted by frequency of use as follows:

will, can, would, could, must, should, may, might, shall

Generally speaking, modal verbs, such as can, could, may, might mostly express possibility in academic writing, especially suggesting the writer's uncertainty toward his or her academic view. While modal verbs must, should emphasize the individual obligation. Modal verbs will, would, shall mainly express prediction in academic writing. 
Will and can are the first two most frequently used modal verbs in EAPFM, and might is the most rarely used modal verb, which is exactly same with what will and can are used in BAWE. Those features are consistent with characteristics of modal verbs in academic writing. However, would is found to be less used, while should is overused in EAPFM. The possible reason, according to author, is that those of fashion majors are greatly affected by the native language in learning English due to lack of English-speaking environment. Therefore, they are more likely to use the modal verbs of obligation which are more didactic or lecture-based, and especially emphasize the obligation of others or themselves. On the other hand, should in Chinese usually indicates uncertainty of the speaker about what he or she says or believes, it often implies possibility and speculation more than certainty, this in turn reflects lack of the confidence in their research topic, which is closely related to the way of inactive learning on Chinese Campus. Compared with will, would is usually used in the way of euphemism and discussion, leaving room for the statement to avoid imposing the inference or view on others. According to the study, postgraduates of fashion major are more likely to use will with the stronger affirmation in academic writing instead of would. Using will is to emphasize the reliability of the study so that the research result can be generally recognized by the readers. Chinese characters Keyi (which means can in English) suggests having achieved the ability to do something on one hand, on the other hand, it means possibility in objectivity, sometimes, it points to suggestions. Obviously, in academic writing, the usage of can is greatly affected by Chinese. Can used the most frequently in EAPFM in most cases suggests the positive attitude of those postgraduates toward the study, and also implies their strong self-confidence in the research topic. When expressing possibility in academic writing, Chinese students prefer to choose can instead of might, that's why might is used the least frequently in the nine central modals.

\section{Conclusion}

In this study, the micro features of English abstracts of postgraduates of fashion majors and that of English speaking experts are analyzed and compared by using software of Range and LLX2 in terms of lexical variation, lexical density of general words and academic words, and modal verbs. The research result shows the coverage of academic words in EAESE is larger than that in EAPFM. Compared with the frequency of central modal verbs in BAWE, there is the significant difference between the eight central modal verbs except shall. In the meantime, modal verb of obligation should and modal verb emphasizing reliability will are overused in EAPFM while modal verbs expressing euphemism would is less used in academic writing. The most frequently used modal verb can in EAPFM shows the stronger confidence in the research topic.

Above all, the empirical research of lexical features in academic writing based on corpus greatly enriches academic abstract researches of theses, and the result of the research can definitely provide postgraduates English teaching with beneficial implication, and the strong evidence, raising awareness of genre. Of course, more related empirical researches are required to enrich lexical studies of abstracts, providing more data support. 


\section{Acknowledgement}

The research is financed by the project of Construction of English Abstract Writing Ability of Thesis for Postgraduates of Art (J2017-13) and the project of Exploratory Course of Costume English Based on Blended Teaching Mode. (XXTD-1607).

\section{References}

Bhatia, V. K. (1993). Analyzing Genre: Language Use in Professional Settings. London: Longman Press.

Biber, D., Johansson, S., \& et. al. (2000). Longman Grammar o Spoken and Written English. Beijing: Foreign Language Teaching and Research Press.

Chen, M. Z. (2016). The grammatical category of English basic modal verbs and its past tense from the perspective of conceptual integration theory. Journal of PLA University of Foreign Languages, 1, 54-61. I

Cao, Y., \& Xiao Z. H. (2015). The multidimensional analysis of research article abstracts of native English writers and Chinese writers. Foreign Language Education, 6, 5-9. https://doi.org/10.16362/j.cnki.cn61-1023/h.2015.06.002

Chen, X. W., \& Wang L. L. (2017). The corpus-based rhetoric comparison and translation of abstracts of technical articles. Chinese Science and Technology Translators Journal, 2, 32-35. https://doi.org/10.16024/j.cnki.issn1002-0489.2017.01.010

Fowler, R. (1979). Language and Control. London: Routledge \& Kegan Paul.

Guo, H., \& Ma L. (2016). The cultural and paradigmatic variations of English abstracts of English writers and Chinese writers from journals in sociology. Journal of $X i$ ' an International Studies University, 4, 39-43. https://doi.org/10.16362/j.cnki.cn61-1457/h. 2016.04.009

Graetz, N. (1985). Teaching EFL students to extract structural information from abstracts. In Ulijn J. M., \& Pugh A. K. (eds.), Reading for Professional Purposes: Methods and Materials in Teaching Languages. Leuven: Acco, 123-135.

Hilary, G. (2010). Science Research Writing: A Guide for Non-Native Speakers of English. London: Imperial College Press.

$\mathrm{Hu}, \mathrm{X}$. (2015). A comparative study on lexical characteristics in different moves of English abstracts by Chinese and English writers. Modern Foreign Languages, 6, 813-822.

Li, P., \& Josta van Rij-Heyligers. (2011). Corpus-based genre analysis of research abstracts written in English byfirst and second / foreign language speakers of English. Journal of Xi' an International Studies University, 3, 39-44. https://doi.org/10.16362/j.cnki.cn61-1457/h. 2011.01.024

Li, G. J., \& Cao Y. (2015). A study of structure and function of lexical bundles in abstracts of 
scientific and technical journals. Journal of China University of Petroleum, 2, 80-85. https://doi.org/10.13216/j.cnki.upcjess.2015.01.0015

Liu, S. F. (2011). Self-referencing and identity of English and Chinese research article abstracts. Modern Rhetoric, 4, 85-88. https://doi.org/10.16027/j.cnki.cn31-2043/h. 2011.04.013

Liu, Q., \& Wang X.Y. (2016). Shell nouns in abstracts of academic writing of science and engineering majors. Foreign Language World, 2, 52-60.

Liu, H. P., \& Xu Y. C.. (2015). The stylistic features of English abstracts in academic articles of humanities \& social sciences---take abstracts of SSCI and A \& HCI journal articles as the example. Journal of Xi'an International Studies University, 12, 46-50. https://doi.org/10.16362/j.cnki.cn61-1457/h.2015.04.012

Liu, Y. H., \& Zhang Y. (2016). The contrastive studies of the abstracts in international academic journal articles by Chinese and English-speaking scholars. Foreign Language World, 5, 20-27.

Long, S. B., Fu, H. B., Chen, T. Z., \& Wang, C. (2016). A Corpus-based Study of the Modal Verbs in English Majors' Argumentative Essays. Foreign Language Research, 1, 124-131. https://doi.org/10.16263/j.cnki.23-1071/h.2016.01.025

Lv, Ying. (2017). Medical abstracts written by Chinese and international writers: A corpus-driven study on formulaic sequences. Media in Foreign Language Instruction, 2, 78-82.

$\mathrm{Mu}, \mathrm{C}$. J. (2016). A comparative study of rhetorical relations in English and Chinese research article abstracts: A Rhetorical Structure Theory perspective. Modern Foreign Languages, 2, 97-107.

Niu, G. L. (2013). Corpus Building and Application of English Abstracts of English and Chinese Academic Writings. Beijing: Intellectual Property Publishing House, 9-10.

Niu, G. L. (2013). New perspective in research on journal article abstracts. Journal of Henan University, 5, 150-156. https://doi.org/10.15991/j.cnki.411028.2013.05.015

Sun, L. (2015). Pragmatic identity construction of English abstracts in Chinese thesis writing. Foreign Languages and Their Teaching, 15, 15-21. https://doi.org/10.13458/j.cnki.flatt.004164

Swales, J. (1990). Genre Analysis: English in Academic and Research Settings. Cambridge: CUP.

Swales, J., \& Feak, C. (1994). Academic Writing for Graduate Students: Essential Tasks and Skills. MI: University of Michigan Press.

Swales, J. M. (2004). Research Genres: Explorations and Applications. Cambridge: Cambridge University Press, 28. 


\section{Macrothink}

Swales, J. M., \& C. B. Feak. (2010). From Text to Task: Putting Research on Abstracts to Work. In Miguel F. Ruiz-Garrido, Juan C. Palmer-Silveira, Inmaculada Fortanet-Gomez (eds.), English for Professional and Academic Purposes. Amsterdam, New York: Rodopi.

Wang, L. (2014). The textual analysis of the abstracts in English academic papers. Foreign Language Research, 3, 111-113.

Wales, J. M. (2001). Genre Analysis: English in Academic and Research Settings. Shanghai: Shanghai Foreign Language Education Publication.

Xiao, Z. H., \& Cao, Y. (2014). A multidimensional contrastive move analysis of English abstracts by Chinese and English writers. Foreign Language Teaching and Research, 2, 260-272.

Ye, H. (2016). The features and usage of English abstract in medical academic articles. Journal of Fujian Medical University (Social Science Edition), 1, 51-54.

Zhou, Z. L. (2015). Corpus-based modal verbs features in English abstracts of Chinese academic papers. Foreign Language and Translation, 2, 45-51.

\section{Copyright Disclaimer}

Copyright for this article is retained by the author(s), with first publication rights granted to the journal.

This is an open-access article distributed under the terms and conditions of the Creative Commons Attribution license (http://creativecommons.org/licenses/by/3.0/). 